\title{
HEALTH PROBLEMS IN A DAY CARE CENTER
}

\section{AC Guedes, A Souza, RBF Guastaldi, PSS Sampaio, CA Borghi, T Ártico \\ Paulista University - Science Health Institute - São Paulo - Brazil}

\section{Background and Aims}

In the early years of life, children are more vulnerable due to the immaturity of the immune, physiological and motor systems. Insertion into the school environment requires interdisciplinary educators knowledge. This research purposes were:

$\checkmark$ To identify the prevalent health problems in day care center and

$\checkmark$ To verify the management of this problems.

\section{Method}

This quantitative, descriptive study was conducted in a day care center in São Paulo where 250 children were matriculated. Data were collected from february to june of 2017, from a book register where all of day care health problems were notified.

\section{Results}

A total of 541 health intercurrences were identified during one semester. Figure 1 shows the most frequent intercurrences, which represented more than $5 \%$ of the total.

Figure 1: Distribution of the most frequent types of health intercurrences in a day care
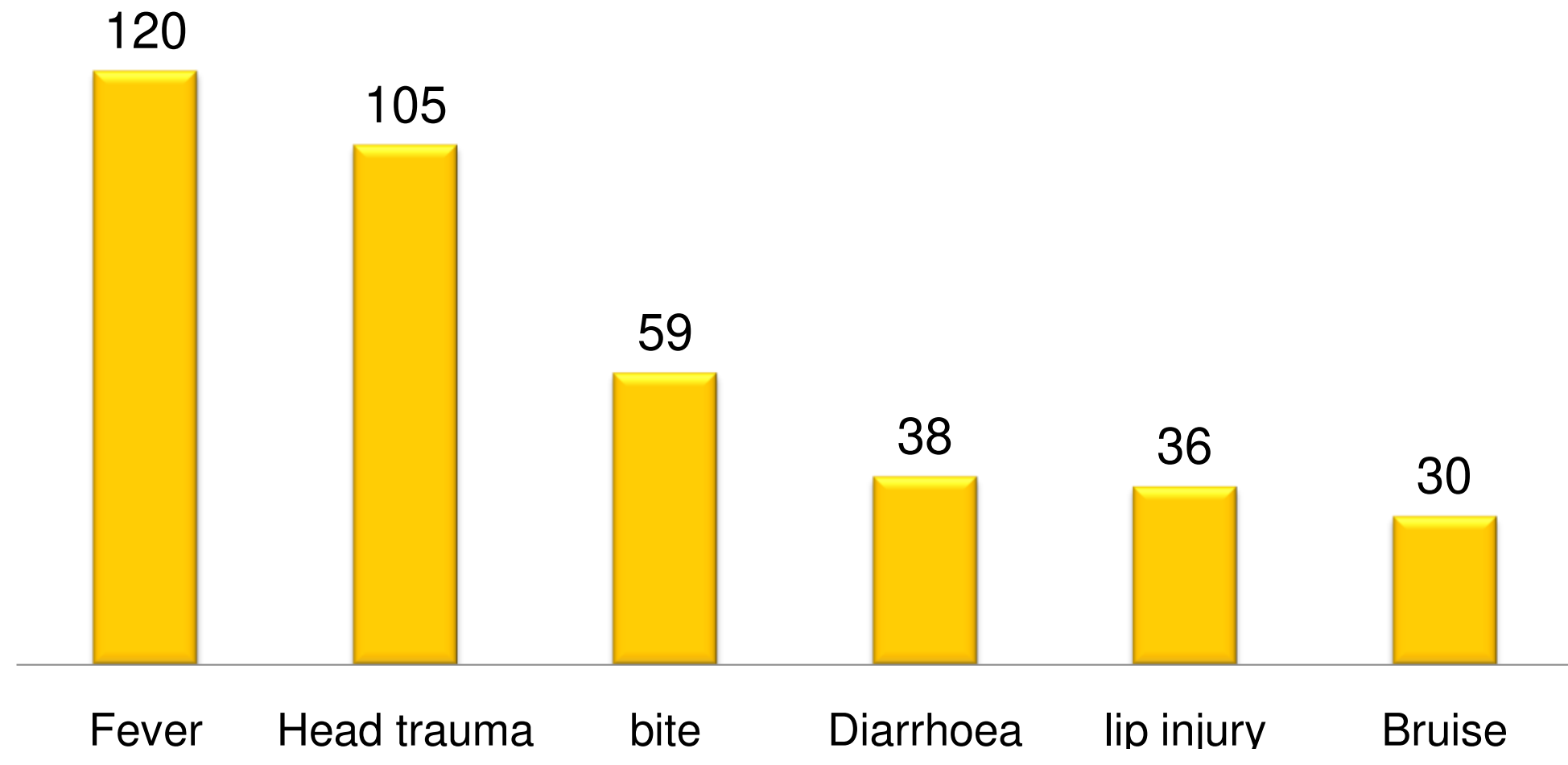

Font: Author, 2018

In front of the 388 intercurrences listed in Figure 1, 101 of them no other conduct was applied. The main behavior implemented by the school for each of the intercurrences is described in Table 1:

Table 1: Distribution of the intercurrences, conducts and frequence in a day care

\begin{tabular}{llcc}
\multicolumn{1}{c}{ Intercorrence } & \multicolumn{1}{c}{ Conduct } & Frequence & $\%$ \\
\hline Fever & Drug Administration & 57 & $47,50 \%$ \\
Head trauma & Cold compress & 78 & $74,30 \%$ \\
Bite & Cold compress & 25 & $42,40 \%$ \\
Diarrhoea & Warning to parents & 14 & $36,80 \%$ \\
Lips injury & Lesion cleaning & 11 & 30,5 \\
Bruise & Lesion cleaning & 15 & $50,00 \%$ \\
\hline
\end{tabular}

Font: Author, 2018

\section{Conclusions}

There're a lot of health problems used to occur in the school. Nursing professional can contribute through the construction of assistance plans and updating the knowledge for the preservation and promotion of children's health in the school. 